\title{
Higher One-year Achievement Rate of Serum Phosphate Associated with Lower Cardiovascular Mortality in Hemodialysis Patients
}

\section{Weichen Zhang}

Fudan University

Guoxin Ye

Fudan University

Zhaori Bi

Fudan University

Weisheng Chen

Fudan University

Jing Qian

Fudan University

Minmin Zhang

Fudan University

Ding Ding

Fudan University

Mengjing Wang ( $\nabla$ fiyona27@126.com )

Fudan University

Jing Chen

Fudan University

\section{Research Article}

Keywords: Achievement rate of serum phosphate, Cardiovascular mortality, Relative weights, Mineral and bone metabolism disorders

Posted Date: June 17th, 2021

DOl: https://doi.org/10.21203/rs.3.rs-618500/v1

License: (c) (1) This work is licensed under a Creative Commons Attribution 4.0 International License.

Read Full License 
Version of Record: A version of this preprint was published at BMC Nephrology on December 1st, 2021. See the published version at https://doi.org/10.1186/s12882-021-02547-z. 


\section{Abstract}

Background: Estimation of phosphate load in hemodialysis patients is always controversial in clinical practice. The aim of this study was to verify individual achievement rate of serum phosphate as the evaluation of phosphate load through investigating its impact on cardiovascular mortality in hemodialysis patients.

Methods: This was a single-center, retrospective cohort study. A total of 251 maintenance hemodialysis patients were enrolled. The individual achievement rate of serum phosphate was defined as the times of tests within the target range divided by total times of tests over a period of time. Cox regression model was used to examine the relationship between individual achievement rate of serum phosphate and cardiovascular mortality.

Results: The mean age of the study population was $61 \pm 13$ years old. A total of $44(17.5 \%)$ patients died from cardiovascular disease (CVD) during a median follow-up of 65 months. Multivariable Cox analysis showed that one-year serum phosphate achievement rate of $0 \%(\mathrm{HR}=4.117, \mathrm{P}=0.016)$ and $25 \%$ $(H R=3.343, P=0.023)$ increased the risk of cardiovascular mortality while the achievement rate of $50 \%$ $(H R=2.129, P=0.162)$ and $75 \%(H R=1.080, P=0.902)$ did not, compared to the rate of $100 \%$. Urea reduction ratio (URR) was positively, while serum intact parathyroid hormone (iPTH), alkaline phosphatase (ALP), normalized protein catabolic rate (nPCR), and total phosphate-binding capacity of drug were negatively associated with achievement in target of serum phosphate.

Conclusions: Keeping one-year achievement rate of serum phosphate higher than $50 \%$ provides significant clinical benefits in reducing cardiovascular mortality.

\section{Introduction}

Hyperphosphatemia is one of common complications in maintenance hemodialysis (MHD) patients which causes poor prognosis. Epidemiological investigations demonstrated that the prevalence of hyperphosphatemia in hemodialysis patients was $30-70 \%[1,2]$ among different countries. It is obvious that serum phosphate level is far from well-controlled worldwide. This may be due to the exchange between serum phosphate and phosphate pool. Phosphate pool includes the phosphate which resides in extracellular compartments except for serum and bone[3]. Researchers believe that phosphate pool may reflect phosphate retention since it explains the rebound of serum phosphate level after hemodialysis treatment[4]. However, phosphate pool cannot be measured, and the association between phosphate pool and serum phosphate level remains uncertain. Thus, we propose that phosphate load, which contains phosphate pool and serum phosphate, is a biomarker for phosphate retention in hemodialysis patients.

Serum phosphate level is considered as an indicator for phosphate overload which is significantly associated with poor prognosis, especially the cardiovascular mortality[5-9]. However, single-time serum phosphate level seems not to be an ideal biomarker for phosphate overload. Dialysis Outcomes and Practice Patterns Study (DOPPS) found that increased serum phosphate level over $6.0 \mathrm{mg} / \mathrm{dL}$ was 
associated with increased all-cause mortality[10]. So as J Park, et al.[11] and $\mathrm{H}$ Wang, et al.[12] But K Kalantar-Zadeh, et al.[13] found serum phosphate concentration was not correlated with cardiovascular mortality in younger MHD patients. Recently, researchers have proposed other biomarkers besides serum phosphate level to assess phosphate overload. For instance, time-dependent serum phosphate (< $3.5 \mathrm{mg} / \mathrm{dl}$ or $\geq 7.0 \mathrm{mg} / \mathrm{dL})[7]$ and time-averaged serum phosphate level $(<3.5 \mathrm{mg} / \mathrm{dl}$ or $>5.5 \mathrm{mg} / \mathrm{dl})[14]$ are proved to be related with increased mortality. Unfortunately, the above biomarkers are a little confused and inconvenient to guide clinical practice. A practical method for phosphate load assessment is urgently needed.

Kidney Disease Outcomes Quality Initiative (KDIGO) Guideline[14] suggests lowering phosphate levels toward the normal range $(2.5-4.5 \mathrm{mg} / \mathrm{dL})$ in 2017 [14], and serum phosphate was recommended to be examined every 1 to 3 months for MHD patients. We proposed the conception "individual achievement rate of serum phosphate" which was defined as the proportion of serum phosphate levels within the target range $(2.5-4.5 \mathrm{mg} / \mathrm{dL})$ during a follow-up period for an individual patient. We supposed that "individual achievement rate of serum phosphate" would be more appropriate to reflect phosphate overload of a hemodialysis patient than other parameters of phosphate and was associated with the poor prognosis.

Thus, the primary aim of this study was to investigate the association of achievement rate of serum phosphate with cardiovascular mortality in hemodialysis patients. Besides, we explored the relative weights of related factors associated with achievement of serum phosphate in target range.

\section{Methods}

\section{Study population}

This was a single-center, retrospective cohort study. Patients receiving hemodialysis treatment for at least 3 months in Huashan Hospital from January 2012 to September 2019 were enrolled. Patients enrolled in January 2012 were divided into the previous group with exposure period from January 2012 to December 2012. Patients enrolled after January 2012 were divided into the new group with exposure period during the first year after enrollment. Exclusion criteria included age $<18$ or $>85$ years old, residual urine volume $>100 \mathrm{ml} / \mathrm{d}$ and missing data on key parameters including serum calcium, phosphate and iPTH. The patients flow chart was shown in Supplemental Table 1. A total of 336 patients on MHD were screened and 251 patients were finally enrolled in this study. The study was approved by the Ethics Committee on Human Research of Huashan Hospital, Fudan university (KY2021-584). Study design were shown in Supplemental Fig. 2.

\section{Data collection, evaluation of individual achievement rate of serum calcium, phosphate and parathyroid hormone}

Demographic, dialysis-specific and laboratory data were collected from electronic database of Hemodialysis Center. Patients in our center were followed regularly in January, April, July, and October 
with biochemical and immunological testing for the regular assessment of complications every year. The following laboratory parameters were determined: hemoglobin $(\mathrm{Hb})$, serum calcium, phosphate, intact parathyroid hormone (iPTH), alkaline phosphatase (ALP), albumin (Alb), prealbumin (PAB), highsensitivity C-reactive protein (hs-CRP) and N-terminal pro-B-type natriuretic peptide (NT-proBNP). The results of the first examination after enrollment within three months were considered as the baseline. The first year after enrollment was considered as the exposure period and the biochemical data during this period were included into analysis as predictors.

Blood samples were obtained at the beginning of dialysis on the day of the midweek HD session and all laboratory values were measured using Hitachi clinical chemistry analyzer (Tokyo, Japan) with standard laboratory techniques. The corrected calcium was calculated using the following formula[17]: Corrected $\mathrm{Ca}^{2+}(\mathrm{mmol} / \mathrm{L})=$ Measured $\mathrm{Ca}^{2+}(\mathrm{mmol} / \mathrm{L})+[40-$ measured serum albumin $(\mathrm{g} / \mathrm{L})] \times 0.02$. The urea reduction ratio (URR) was calculated with the formula $100 \times\left(1-\left[\mathrm{C}_{t} / \mathrm{C}_{0}\right]\right)[18]$, in which $\mathrm{C}_{\mathrm{t}}$ was the blood urea nitrogen measured at the end of dialysis and $\mathrm{C}_{0}$ was the pre-dialysis blood urea nitrogen. The single-pool $\mathrm{Kt} / \mathrm{V}$ delivered by HD (spKt/ $\mathrm{V}_{\text {urea }}$ ) was estimated by the second-generation Daugirdas formula[19]. The normalized protein nitrogen appearance (nPNA) was calculated by the method described by Termorshuizen et al.[20] and normalized to standard body weight[21]. Total phosphate-binding capacity was defined as the product of dose of phosphate binders which a patient took per day and the amount of phosphate removal per tablet[22]. Meanwhile, the dose of calcitriol and the usage of cinacalcet were also recorded in the baseline and the routine follow-up.

According to the KDIGO guideline[15], the target level of serum calcium and phosphate were suggested towards the normal range while the target level of iPTH was 150 to $300 \mathrm{pg} / \mathrm{ml}$. The individual achievement rate of serum calcium, phosphate and iPTH was defined as the times of tests within the target range divided by total times of tests over a period of time. For instance, the calculation of one-year achievement rate of serum phosphate was the target-achieving times divided by the total four times in one year since we tested quarterly; long-term serum phosphate achievement rate was calculated by the target-achieving times divided by the number of tests in the whole follow-up period. The mean serum phosphate level and serum phosphate variability were also included in analysis. The mean serum phosphate level was defined as the average value of serum phosphate over one year or the whole followup period and serum phosphate variability was the coefficient of variation during the analysis period (CV, standard deviation/mean).

Cardiovascular mortality was regarded as the primary endpoint, defined as death due to acute myocardial infarction, pericarditis, cardiac tamponade, atherosclerotic heart disease, cardiomyopathy, cardiac arrhythmia, cardiac arrest, valvular heart disease, pulmonary edema, congestive heart failure or stroke. Enrolled patients were followed up from January 2012 to the day of censoring for death, transplantation, peritoneal dialysis, transferring to another center, or the end of the study (September 30th 2020).

\section{Statistical Analyses}


Quantitative variables were expressed as mean \pm SD or as median (IQR), while categorical variables were expressed as percentages or ratios. The differences between groups were examined using $\chi 2$ test, independent $t$ test or Kruskal-Wallis test appropriately. Crude hazard ratios (HR) for mortality was determined using univariable Cox regression model. Those parameters with $P<0.05$ were selected to the multivariable stepwise Cox regression model to identify the independent risk factors and calculate the adjusted HR.

Random-intercept logistic mixed-effects models[23] were used to analyze the associations between achievement in target of serum phosphate (whether or not one patient meets the target of serum phosphate each time) and proposed risk factors. We included visit as a fixed categorical effect, and a random intercept for each subject in the model. Those parameters with $P<0.05$ from the univariate analyses, in combination with the clinical relevance consideration, were selected to the multivariate logistic mixed-effects model[24]. Unadjusted and adjusted odds ratios (OR) as well as the 95\% confidence interval $(95 \% \mathrm{Cl})$ were reported.

We explored the relative weights of related factors according to the standardized regression coefficients[25]. Logistic mixed-effects model which contained standardized variables was used to determine the relative weights of these factors. The standardized regression coefficients of the mixedeffects model were added as the total weight and the relative weights was calculated as the percentage of each variable in the total weight[26].

All analyses were performed using SPSS version 19 (Chicago, IL, USA) and Stata version 13 (College Station, TX, USA). A p-value of less than 0.05 was considered statistically significant.

\section{Results}

\section{Baseline characteristics}

A total of 251 hemodialysis patients from Huashan Hospital were enrolled in this study including 178 patients receiving hemodialysis before research (previous group) and 73 patients new to hemodialysis (new group). As Table 1 presented, the hemodialysis patients had a mean age of $61 \pm 13$ years old, $53.4 \%$ were male, $21.9 \%$ had diabetes mellites, and $34.7 \%$ had cardiovascular disease. Mean ( \pm SD) serum calcium, phosphate and iPTH in the first year after enrollment were $2.45 \pm 0.15 \mathrm{mmol} / \mathrm{L}, 1.77 \pm 0.38$ $\mathrm{mmol} / \mathrm{L}$ and $309.5 \pm 167.8 \mathrm{pg} / \mathrm{ml}$, respectively. Patients in previous group had higher dialysis age $[73.23(34.69,134.17)$ vs. 0 month, $P<0.001]$ and NT-proBNP $[7081(3441,18204)$ vs. $3744(2631,8483)$ $\mathrm{pg} / \mathrm{ml}, \mathrm{P}=0.002$ ] but lower serum albumin $(38.85 \pm 3.25 \mathrm{vs}$. $39.91 \pm 3.54 \mathrm{~g} / \mathrm{L}, \mathrm{P}=0.008)$. Meanwhile, the percentage of diabetes mellites was higher in patients new to hemodialysis $(16.9 \%$ vs. $34.2 \%, P=0.002)$. There were no significant differences of other characteristics between two groups.

The mean of individual one-year achievement rate of serum calcium, phosphate and iPTH were $68.7 \%$, $51.7 \%$ and $52.5 \%$, respectively (Supplemental Figure 3 ). A total of $44(17.5 \%)$ patients died from CVD during a median follow-up of 65 months. 


\section{Serum phosphate achievement rate had higher predictive value than other parameters for cardiovascular mortality}

In the unadjusted Cox model (Table 2), higher one-year achievement rate of serum phosphate was associated with lower risk of CVD mortality. Compared with one-year serum phosphate achievement rate of $100 \%$, patients with rate of $0 \%(H R=4.381,95 \% \mathrm{Cl}=1.179-17.283, \mathrm{P}=0.018)$ and $25 \%(\mathrm{HR}=3.244$, $95 \% \mathrm{Cl}=1.156-9.105, \mathrm{P}=0.025)$ had a higher risk of CVD mortality. Besides, higher long-term serum phosphate achievement rate $(\mathrm{HR}=0.248,95 \% \mathrm{Cl}=0.078-0.791, \mathrm{P}=0.018)$ was also related to lower risk of CVD mortality (Figure 1A, Supplemental Table 1). However, we did not find any association between CVD mortality and other parameters of calcium, phosphate and iPTH (Table 2).

\section{Serum phosphate achievement rate was negatively associated with cardiovascular mortality}

Univariate Cox analysis showed age, sex, diabetes mellitus, cardiovascular disease, history of kidney transplantation, one-year serum phosphate achievement rate, one-year mean of Alb, PAB, hs-CRP, NTproBNP, spKt/V and URR were associated with cardiovascular mortality (Table 3). Stepwise multivariable Cox analysis further demonstrated that age ( $\mathrm{HR}=1.049, \mathrm{P}=0.005,95 \% \mathrm{Cl}: 1.015-1.084)$, diabetes mellitus $(\mathrm{HR}=1.979, \mathrm{P}=0.039,95 \% \mathrm{Cl}: 1.036-3.778)$ and cardiovascular disease $(\mathrm{HR}=2.790, \mathrm{P}=0.002,95 \% \mathrm{Cl}: 1.468-$ $5.303)$ increased the risk of cardiovascular mortality while lower Alb ( $\mathrm{HR}=0.848, \mathrm{P}=0.002,95 \% \mathrm{Cl}$ : 0.762 0.943) were associated with higher CVD mortality. Besides, we found that hazard ratio for cardiovascular mortality was $4.117(95 \% \mathrm{Cl}=1.305-12.986, \mathrm{P}=0.016)$ in patients with one-year serum phosphate achievement rate of $0 \%, 3.343(95 \% \mathrm{Cl}=1.177-9.494, \mathrm{P}=0.023)$ in patients with rate of $25 \%, 2.129$ $(95 \% \mathrm{Cl}=0.738-6.144, \mathrm{P}=0.162)$ in patients with rate of $50 \%$ and $1.080(95 \% \mathrm{Cl}=0.318-3.665, \mathrm{P}=0.902)$ in patients with rate of $75 \%$ compared to the reference group with rate of $100 \%$ (Table 3, Figure 1B) Similar result was obtained for long-term serum phosphate achievement rate (Supplemental Table 2). Meanwhile, two additional adjustment models were performed since dialysis age and NT-proBNP were significantly different between previous group and new group (Supplemental Table 3). In both models, one-year achievement rate of serum phosphate was significantly associated with cardiovascular mortality.

\section{ALP, iPTH, nPCR, URR, and total phosphate-binding capacity were related with target achievement of serum phosphate}

Logistic mixed-effects regression model was further used to explore the related factors of target achievement of serum phosphate during the first year. We found that serum iPTH level $(H R=0.922$, $\mathrm{P}<0.001,95 \% \mathrm{Cl}: 0.903-0.950)$, ALP (HR=0.957, $\mathrm{P}<0.001,95 \% \mathrm{Cl}: 0.967-0.983), \mathrm{nPCR}(\mathrm{HR}=0.114, \mathrm{P}<0.001$, 95\% Cl: 0.036-0.366), URR ( $\mathrm{HR}=2.259, \mathrm{P}=0.007,95 \% \mathrm{Cl}: 2.393-3.924)$ and total phosphate-binding capacity of drug (HR=0.997, $\mathrm{P}=0.023,95 \% \mathrm{Cl}: 0.995-0.999)$ were significantly correlated with target achievement of serum phosphate (Table 4). Relative weights analysis of related factors was presented in Figure 2. Serum ALP level which contributed to $35.4 \%$ of the total weights had the greatest impact on target achievement of serum phosphate during the first year. Other parameters including iPTH, nPCR, URR, and total phosphate-binding capacity contributed to $21.1 \%, 16.6 \%, 15.9 \%$, and $11.0 \%$, respectively. 


\section{Discussion}

In this retrospective analysis of 251 patients with maintenance hemodialysis, we found that individual achievement rate of serum phosphate had stronger predictive value for cardiovascular mortality than traditional calcium, phosphate and iPTH parameters. Hemodialysis patients with one-year target achievement rate of phosphate lower than $50 \%$ had higher cardiovascular mortality. Furthermore, serum iPTH level, ALP, nPCR, URR and total phosphate-binding capacity of drug were significantly correlated with target achievement of serum phosphate while serum ALP provided the largest contribution to target achievement of serum phosphate

Single time-point measurement may not be an accurate biomarker of phosphate overload. Increased PTH, fibroblast growth factor 23 (FGF-23) and decreased Klotho, 1,25 dihydroxy vitamin D (1,25D) which regulate bone metabolism result in serum phosphate fluctuation[27, 28]. Moreover, Short-time high phosphate diets can alter the level of serum phosphate immediately [29, 30]. In addition, studies have found that the efficiency of phosphate binders varied from patients to patients. Thus, we propose that one-year achievement rate of serum phosphate instead of other parameters to reflect the status of phosphate metabolism in MHD patients accurately.

There are several reasons which may explain why one-year achievement rate of serum phosphate was appropriate to reflect phosphate metabolism. First, four times measurements are closer to the true state of phosphate control in patients. Second, one-year achievement rate of serum phosphate may indicate both serum phosphate level and serum phosphate variability. Serum phosphate level[31] and serum phosphate variability[32] are vital parameters for phosphate metabolism. If serum phosphate level fluctuates wildly during a period, serum phosphate is far from controlled although the time-averaged serum phosphate level may be normal. To some extent one-year achievement rate of serum phosphate can represent serum phosphate variability. Finally, the increased risk of cardiovascular mortality by phosphate was not a timely effect but a long-term effect through vascular calcification. One-year achievement rate of serum phosphate can be considered as the long-term effect.

Since achievement rate of serum phosphate is associated with clinical outcome in hemodialysis patients, it is crucial for physicians to improve the achievement rate. In this study, we revealed that serum iPTH level, ALP, nPCR, URR and total phosphate-binding capacity of drug were main factors related with target achievement of serum phosphate. Among those factors, ALP had the largest relative weights while iPTH followed closely. As we know, ALP is generally considered as a nonspecific biomarker of bone metabolism[33]. S Salam, et al.[34] studied diagnostic accuracy of bone biomarkers, finding that total ALP could predict bone turnover with an area under curve (AUC) of 0.753 . Other observational study also indicated that ALP was correlated with hungry bone syndrome[35] and chronic kidney disease-mineral metabolism disorder (CKD-MBD)[36]. Meanwhile, PTH plays a vital role in bone metabolism. S Salam, et al.[34] analyzed bone samples from 492 dialysis patients and demonstrated that iPTH was able to discriminate both low and high bone turnover from normal bone turnover. P Ivarsen et al.[37] reached the conclusion that PTH promoted bone resorption and was negatively associated with bone density. Basic 
research concluded similarly that elevated PTH led to reduced bone volume and increased bone turnover[38]. Thus, PTH may affect serum phosphate fluctuation through the impact on absorption and release of phosphate from bone. Our research found iPTH and ALP together occupied nearly $60 \%$ relative weights of target achievement of serum phosphate, illustrating that bone phosphate release contributed greatly to phosphate burden. Thus, to treat abnormal bone metabolism might be the major phosphatelowing strategy. Another important factor is nPCR which reflects dietary protein intake[39]. Our results indicated nPCR occupied $16.6 \%$ relative weights for target achievement of serum phosphate, which meant restricted dietary phosphate intake was also essential for management of hyperphosphatemia. Similarly, URR and total phosphate-binding capacity of drug occupied $15.9 \%$ and $11.0 \%$ relative weights respectively, which indicated that dialysis adequacy and phosphate binders were useful for management of hyperphosphatemia as well. Though the above findings emphasize again the "3D" principles management of hyperphosphatemia, they also add strength to the order of treatment strategies.

In this study, we found that lower achievement rate of serum phosphate was an independent risk factor for cardiovascular mortality in maintenance hemodialysis patients. Therefore, it is urgent for physicians to take effective measures to improve such achievement rate. According to our results, we believe that keeping the one-year achievement rate of serum phosphate higher than $50 \%$ provides significant clinical benefits in reducing cardiovascular mortality. On one hand, compared with one-year serum phosphate achievement rate of $100 \%$, the risk of cardiovascular mortality increased when achievement rate was $0 \%$ and $25 \%$ while it was not significantly different when achievement rate was $50 \%$ and $75 \%$. On the other hand, the average one-year serum phosphate achievement rate of enrolled patients in this study was only $51.7 \%$, which meant the achievement rate of many patients was less than $50 \%$. It was difficult to raise one-year serum phosphate achievement rate up to $100 \%$ for all maintenance hemodialysis patients because of huge economic costs. Thus, we believe that it is an appropriate choice for physicians to keep the one-year achievement rate of serum phosphate higher than $50 \%$ of maintenance hemodialysis patients. This is also the major clinical value of this study.

Limitations to our study should be acknowledged. Firstly, due to the retrospective, observational nature of this study, we cannot prove causality between achievement rate of serum phosphate and CVD mortality. Secondly, our study was executed at single hemodialysis center in Huashan Hospital with a limited sample. Multicenter, prospective cohort study is needed. Finally, there may also be residual confounding or unmeasured confounders such as FGF-23 and vitamin D. In addition, we enrolled patients without residual renal function in this study. Thus, the association of achievement rate of serum phosphate with CVD mortality in patients with residual renal function needs to be further investigated.

In conclusion, we demonstrate for the first time that achievement rate of serum phosphate is negatively correlated with cardiovascular mortality in maintenance hemodialysis patients. Keeping the one-year achievement rate of serum phosphate higher than $50 \%$ provides significant clinical benefits in reducing cardiovascular mortality. Achievement rate of serum phosphate is proved to be a more accurate indicator for phosphate load in maintenance hemodialysis patients, which is widely applicable for clinical practice. 


\section{Abbreviations}

CVD, cardiovascular disease; iPTH, intact parathyroid hormone; ALP, alkaline phosphatase; nPCR, normalized protein catabolic rate; URR, urea reduction ratio; MHD, maintenance hemodialysis; DOPPS, Dialysis Outcomes and Practice Patterns Study; KDIGO, Kidney Disease Outcomes Quality Initiative; HB, hemoglobin; Alb, albumin; PAB, prealbumin; hs-CRP, high-sensitivity C-reactive protein; NT-proBNP, Nterminal pro-B-type natriuretic peptide; FGF-23, fibroblast growth factor 23; 1,25D, 1,25 dihydroxy vitamin $\mathrm{D}$; AUC, area under curve; CKD-MBD, chronic kidney disease-mineral metabolism disorder;

\section{Declarations}

\section{Acknowledgements}

The results presented in this article have not been published previously in whole or part, except in abstract format. We thank the staff and participants from Huashan Hospital for providing the clinical data for this research.

\section{Authors' Contributions}

Research idea and study design: Weichen Zhang, Mengjing Wang, Jing Chen; data acquisition: Weichen Zhang, Guoxin Ye, Weisheng Chen, Jing Qian; statistical analysis: Weichen Zhang, Zhaori Bi, Mengjing Wang, Ding Ding; supervision or mentorship: Mengjing Wang, Minmin Zhang, Jing Chen.

\section{Funding}

This work was financially supported by Shanghai medical leading talents project No. 2019LJ03 (Jing Chen), Shanghai municipal science and technology commission researching fund No. 17411950701 (Jing Chen), Three-year action plan to promote clinical skills and clinical innovation capability in municipal hospitals No. SHDC2020CR4014(Mengjing Wang), National Key Research and Development Program No. 2020 YFC2005003 (Jing Chen), Shanghai Medical Engineering Technology Research Center for Aging Diseases with Artificial Intelligence No. 19DZ2251700 (Jing Chen).

\section{Availability of Data and Materials}

The datasets used and/or analyzed during the current study are available from the corresponding author on reasonable request.

\section{Conflict of Interest Statement}

The authors declare that they have no relevant financial interests.

\section{Ethics Approval and Consent to Participate}


The study was approved by the Ethics Committee on Human Research of Huashan Hospital, Fudan university (KY2021-584). Written Informed consent was obtained from all patients enrolled in this study or their families.

\section{Consent for publication}

Not applicable.

\section{References}

1. Okparavero A, Foster MC, Tighiouart H, Gudnason V, Indridason O, Gudmundsdottir H, Eiriksdottir G, Gudmundsson EF, Inker LA, Levey AS: Prevalence and complications of chronic kidney disease in a representative elderly population in Iceland. Nephrology, dialysis, transplantation: official publication of the European Dialysis and Transplant Association - European Renal Association 2016, 31(3):439447.

2. Abrita RR, Pereira BDS, Fernandes NDS, Abrita R, Huaira RMNH, Bastos MG, Fernandes NMDS: Evaluation of prevalence, biochemical profile, and drugs associated with chronic kidney diseasemineral and bone disorder in 11 dialysis centers. Brazilian Journal of Nephrology 2018, 40(1):26-34.

3. Vervloet MG, van Ballegooijen AJ: Prevention and treatment of hyperphosphatemia in chronic kidney disease. KIDNEY INT 2018, 93(5):1060-1072.

4. Agar BU, Akonur A, Lo Y, Cheung AK, Leypoldt JK: Kinetic Model of Phosphorus Mobilization during and after Short and Conventional Hemodialysis. CLIN J AM SOC NEPHRO 2011, 6(12):2854-2860.

5. Rayner HC, Larkina M, Wang M, Graham-Brown M, van der Veer SN, Ecder T, Hasegawa T, Kleophas W, Bieber BA, Tentori F et al: International Comparisons of Prevalence, Awareness, and Treatment of Pruritus in People on Hemodialysis. Clin J Am Soc Nephrol 2017, 12(12):2000-2007.

6. Rivara MB, Ravel V, Kalantar-Zadeh K, Streja E, Lau WL, Nissenson AR, Kestenbaum B, de Boer IH, Himmelfarb J, Mehrotra R: Uncorrected and Albumin-Corrected Calcium, Phosphorus, and Mortality in Patients Undergoing Maintenance Dialysis. J AM SOC NEPHROL 2015, 26(7):1671-1681.

7. Palmer SC, Hayen A, Macaskill P, Pellegrini F, Craig JC, Elder GJ, Strippoli GF: Serum levels of phosphorus, parathyroid hormone, and calcium and risks of death and cardiovascular disease in individuals with chronic kidney disease: a systematic review and meta-analysis. JAMA 2011, 305(11):1119-1127.

8. Nishizawa Y, Jono S, Ishimura E, Shioi A: Hyperphosphatemia and vascular calcification in end-stage renal disease. J RENAL NUTR 2005, 15(1):178-182.

9. ACHINGER SG, AYUS JC: Left ventricular hypertrophy: Is hyperphosphatemia among dialysis patients a risk factor? In: 2006-01-01 2006; Hagerstown, MD: Lippincott Williams \& Wilkins; 2006: S255-S261.

10. Tentori F, Blayney MJ, Albert JM, Gillespie BW, Kerr PG, Bommer J, Young EW, Akizawa T, Akiba T, Pisoni RL et al: Mortality Risk for Dialysis Patients With Different Levels of Serum Calcium, 
Phosphorus, and PTH: The Dialysis Outcomes and Practice Patterns Study (DOPPS). AM J KIDNEY DIS 2008, 52(3):519-530.

11. Streja E, Wang H, Lau WL, Molnar MZ, Kovesdy CP, Kalantar-Zadeh K, Park J: Mortality of combined serum phosphorus and parathyroid hormone concentrations and their changes over time in hemodialysis patients. BONE 2014, 61:201-207.

12. Da J, Xie X, Wolf M, Disthabanchong S, Wang J, Zha Y, Lv J, Zhang L, Wang H: Serum Phosphorus and Progression of CKD and Mortality: A Meta-analysis of Cohort Studies. AM J KIDNEY DIS 2015, 66(2):258-265.

13. Lertdumrongluk P, Rhee CM, Park J, Lau WL, Moradi H, Jing J, Molnar MZ, Brunelli SM, Nissenson AR, Kovesdy CP et al: Association of Serum Phosphorus Concentration With Mortality in Elderly and Nonelderly Hemodialysis Patients. J RENAL NUTR 2013, 23(6):411-421.

14. Lertdumrongluk P, Rhee CM, Park J, Lau WL, Moradi H, Jing J, Molnar MZ, Brunelli SM, Nissenson AR, Kovesdy CP et al: Association of Serum Phosphorus Concentration With Mortality in Elderly and Nonelderly Hemodialysis Patients. J RENAL NUTR 2013, 23(6):411-421.

15. Isakova T, Nickolas TL, Denburg M, Yarlagadda S, Weiner DE, Gutiérrez OM, Bansal V, Rosas SE, Nigwekar S, Yee J et al: KDOQI US Commentary on the 2017 KDIGO Clinical Practice Guideline Update for the Diagnosis, Evaluation, Prevention, and Treatment of Chronic Kidney Disease-Mineral and Bone Disorder (CKD-MBD). AM J KIDNEY DIS 2017, 70(6):737-751.

16. Uhlig K, Berns JS, Kestenbaum B, Kumar R, Leonard MB, Martin KJ, Sprague SM, Goldfarb S: KDOQI US Commentary on the 2009 KDIGO Clinical Practice Guideline for the Diagnosis, Evaluation, and Treatment of CKD-Mineral and Bone Disorder (CKD-MBD). AM J KIDNEY DIS 2010, 55(5):773-799.

17. K/DOQI clinical practice guidelines for bone metabolism and disease in chronic kidney disease. $A M \mathrm{~J}$ KIDNEY DIS 2003, 42(4 Suppl 3):S1-S201.

18. Owen WJ, Lew NL, Liu Y, Lowrie EG, Lazarus JM: The urea reduction ratio and serum albumin concentration as predictors of mortality in patients undergoing hemodialysis. N Engl J Med 1993, 329(14):1001-1006.

19. Daugirdas JT: Second generation logarithmic estimates of single-pool variable volume Kt/V: an analysis of error. J AM SOC NEPHROL 1993, 4(5):1205-1213.

20. Termorshuizen F, Dekker FW, van Manen JG, Korevaar JC, Boeschoten EW, Krediet RT: Relative contribution of residual renal function and different measures of adequacy to survival in hemodialysis patients: an analysis of the Netherlands Cooperative Study on the Adequacy of Dialysis (NECOSAD)-2. J AM SOC NEPHROL 2004, 15(4):1061-1070.

21. Watson PE, Watson ID, Batt RD: Total body water volumes for adult males and females estimated from simple anthropometric measurements. AM J CLIN NUTR 1980, 33(1):27-39.

22. Daugirdas JT, Finn WF, Emmett M, Chertow GM: The Phosphate Binder Equivalent Dose. SEMIN DIALYSIS 2011, 24(1):41-49.

23. Ozechowski TJ, Turner $\mathrm{CW}$, Hops $\mathrm{H}$ : Mixed-effects logistic regression for estimating transitional probabilities in sequentially coded observational data. PSYCHOL METHODS 2007, 12(3):317-335. 
24. Keihani S, Xu Y, Presson AP, Hotaling JM, Nirula R, Piotrowski J, Dodgion CM, Black CM, Mukherjee K, Morris $\mathrm{BJ}$ et al: Contemporary management of high-grade renal trauma. J TRAUMA ACUTE CARE 2018, 84(3):418-425.

25. Li J, Yu J, Chen X, Quan X, Zhou L: Correlations between health-promoting lifestyle and health-related quality of life among elderly people with hypertension in Hengyang, Hunan, China. MEDICINE 2018, 97(25):e10937.

26. Ward MM, Leigh JP: The relative importance of pain and functional disability to patients with rheumatoid arthritis. J RHEUMATOL 1993, 20(9):1494-1499.

27. Felsenfeld AJ, Levine BS, Rodriguez M: Pathophysiology of Calcium, Phosphorus, and Magnesium Dysregulation in Chronic Kidney Disease. Semin Dial 2015, 28(6):564-577.

28. Komaba H, Kaludjerovic J, Hu DZ, Nagano K, Amano K, Ide N, Sato T, Densmore MJ, Hanai JI, Olauson $\mathrm{H}$ et al: Klotho expression in osteocytes regulates bone metabolism and controls bone formation. KIDNEY INT 2017, 92(3):599-611.

29. Vervloet MG, van Ittersum FJ, Buttler RM, Heijboer AC, Blankenstein MA, ter Wee PM: Effects of dietary phosphate and calcium intake on fibroblast growth factor-23. Clin J Am Soc Nephrol 2011, 6(2):383-389.

30. Sigrist M, Tang M, Beaulieu M, Espino-Hernandez G, Er L, Djurdjev O, Levin A: Responsiveness of FGF23 and mineral metabolism to altered dietary phosphate intake in chronic kidney disease (CKD): results of a randomized trial. Nephrol Dial Transplant 2013, 28(1):161-169.

31. Fernandez-Martin JL, Dusso A, Martinez-Camblor P, Dionisi MP, Floege J, Ketteler M, London G, Locatelli F, Gorriz JL, Rutkowski B et al: Serum phosphate optimal timing and range associated with patients survival in haemodialysis: the COSMOS study. Nephrol Dial Transplant 2019, 34(4):673681.

32. Zhu M, Dou L, Zhu M, Liu S, Zhan Y, Lu J, Ni Z, Qian J, Cai H, Zhang W: Variability of serum phosphorus and its association with mortality among hemodialysis patients. CLIN NEPHROL 2018, 90(2):79-86.

33. Dai Z, Wang R, Ang LW, Yuan JM, Koh WP: Bone turnover biomarkers and risk of osteoporotic hip fracture in an Asian population. BONE2016, 83:171-177.

34. Salam S, Gallagher O, Gossiel F, Paggiosi M, Khwaja A, Eastell R: Diagnostic Accuracy of Biomarkers and Imaging for Bone Turnover in Renal Osteodystrophy. J AM SOC NEPHROL 2018, 29(5):15571565.

35. Ge Y, Yang G, Wang N, Zha X, Yu X, Mao H, Sun B, Zeng M, Zhang B, Xing C: Bone metabolism markers and hungry bone syndrome after parathyroidectomy in dialysis patients with secondary hyperparathyroidism. INT UROL NEPHROL 2019, 51(8):1443-1449.

36. Sardiwal S, Magnusson P, Goldsmith DJ, Lamb EJ: Bone alkaline phosphatase in CKD-mineral bone disorder. AM J KIDNEY DIS 2013, 62(4):810-822.

37. Hanne Skou Jørgensen SWMB: Bone turnover markers are associated with bone density, but not with fracture in end stage kidney disease: a cross-sectional study. BMC NEPHROL 2017(18(1):284). 
38. Diaz-Tocados JM, Rodriguez-Ortiz ME, Almaden Y, Pineda C, Martinez-Moreno JM, Herencia C, Vergara N, Pendon-Ruiz DMM, Santamaria R, Rodelo-Haad C et al: Calcimimetics maintain bone turnover in uremic rats despite the concomitant decrease in parathyroid hormone concentration. KIDNEY INT 2019, 95(5):1064-1078.

39. Streja E, Lau WL, Goldstein L, Sim JJ, Molnar MZ, Nissenson AR, Kovesdy CP, Kalantar-Zadeh K: Hyperphosphatemia is a combined function of high serum PTH and high dietary protein intake in dialysis patients. Kidney Int Suppl (2011) 2013, 3(5):462-468.

\section{Tables}

Table 1. Demographic and clinical characteristics of hemodialysis patients 


\begin{tabular}{|c|c|c|c|c|}
\hline Characteristics & Overall( $(\mathrm{N}=251)$ & Previous $(\mathrm{N}=178)$ & $\operatorname{New}(\mathrm{N}=73)$ & $\mathbf{P}$ \\
\hline Age (year) & $61 \pm 13$ & $61 \pm 12$ & $59 \pm 15$ & 0.143 \\
\hline Male (\%) & $133(53.0 \%)$ & $92(51.7 \%)$ & $41(56.2 \%)$ & 0.518 \\
\hline Dialysis age (month) & $37.27(3.33,117.32)$ & 73.23(34.69,134.17) & 0 & $<0.001$ \\
\hline Primary disease (\%) & & & & 0.173 \\
\hline Glomerulonephritis & $87(34.7 \%)$ & $63(35.4 \%)$ & $24(32.9 \%)$ & \\
\hline Diabetes & $41(16.3 \%)$ & $21(11.8 \%)$ & $20(27.4 \%)$ & \\
\hline Hypertension & $39(15.5 \%)$ & $29(16.3 \%)$ & 10(13.7\%) & \\
\hline Polycystic kidney & $27(10.8 \%)$ & $20(11.2 \%)$ & $7(9.6 \%)$ & \\
\hline Other & $57(22.7 \%)$ & $45(25.3 \%)$ & $12(16.4 \%)$ & \\
\hline \multicolumn{5}{|l|}{ Comorbidity } \\
\hline Diabetes mellitus & $55(21.9 \%)$ & $30(16.9 \%)$ & $15(34.2 \%)$ & 0.002 \\
\hline Cardiovascular disease & $87(34.7 \%)$ & $61(34.3 \%)$ & $26(35.6 \%)$ & 0.839 \\
\hline $\begin{array}{l}\text { History of malignant } \\
\text { tumor }\end{array}$ & $26(10.4 \%)$ & 19(10.7\%) & $7(9.6 \%)$ & 0.798 \\
\hline \multicolumn{5}{|l|}{ Laboratory test } \\
\hline $\begin{array}{l}\text { Serum calcium } \\
(\mathrm{mmol} / \mathrm{L})\end{array}$ & $2.45 \pm 0.15$ & $2.46 \pm 0.15$ & $2.41 \pm 0.17$ & 0.21 \\
\hline $\begin{array}{l}\text { Serum phosphate } \\
\text { (mmol/L) }\end{array}$ & $1.77 \pm 0.38$ & $1.79 \pm 0.37$ & $1.72 \pm 0.40$ & 0.075 \\
\hline Serum iPTH (pg/ml) & $309.5 \pm 167.8$ & $311.9 \pm 170.7$ & $280.2 \pm 134.6$ & 0.773 \\
\hline $\operatorname{ALP}(\mathrm{u} / \mathrm{L})$ & $96.42 \pm 71.26$ & $100.65 \pm 64.49$ & $92.11 \pm 85.19$ & 0.181 \\
\hline $\mathrm{Hb}(\mathrm{g} / \mathrm{L})$ & $107.78 \pm 11.81$ & $108.73 \pm 11.44$ & $105.49 \pm 12.43$ & 0.07 \\
\hline Alb (g/L) & $39.16 \pm 3.36$ & $38.85 \pm 3.25$ & $39.91 \pm 3.54$ & 0.008 \\
\hline PAB (mg/L) & $292.99 \pm 74.15$ & $284.97 \pm 73.23$ & $312.46 \pm 73.22$ & 0.071 \\
\hline hs-CRP (mg/L) & $4.25 \pm 3.19$ & $4.45 \pm 3.56$ & $4.04 \pm 3.13$ & 0.34 \\
\hline NT-proBNP (pg/ml) & $5797(3025,16474)$ & $7081(3441,18204)$ & $3744(2631,8483)$ & 0.002 \\
\hline nPCR & $1.13 \pm 0.26$ & $1.13 \pm 0.25$ & $1.12 \pm 0.28$ & 0.672 \\
\hline spKt/V & $1.44 \pm 0.29$ & $1.46 \pm 0.27$ & $1.41 \pm 0.31$ & 0.169 \\
\hline URR & $0.70 \pm 0.08$ & $0.70 \pm 0.07$ & $0.69 \pm 0.09$ & 0.29 \\
\hline Total Phosphate-binding & $88.23 \pm 77.74$ & $92.23 \pm 58.42$ & $83.91 \pm 80.20$ & 0.745 \\
\hline
\end{tabular}


Calcitriol (ug/week)

Cinacalcet
$0.75(0.00,1.88)$
$0.75(0.00,2.15)$

$0.75(0.00,1.25)$

$3(4.1 \%)$

0.16

$17(9.6 \%)$

Note: Values expressed as mean $\pm \mathrm{SD}$, median (IQR) or number(percentage); Previous group included patients received hemodialysis treatment before the research; New group included patients new to hemodialysis.

Abbreviations: $\mathrm{PPTH}$, intact parathyroid hormone; ALP, alkaline phosphatase; Alb, albumin; $\mathrm{Hb}$, hemoglobin; $\mathrm{PAB}$, prealbumin; hs-CRP, high-sensitive $\mathrm{C}$-reactive protein; $\mathrm{nPCR}$, normalized protein catabolic rate; URR, urea reduction ratio. Conversion factors for units: Alb and $\mathrm{Hb}$ in $\mathrm{g} / \mathrm{L} \mathrm{to} \mathrm{g} / \mathrm{dL}, \times 0.1$; calcium in $\mathrm{mmol} / \mathrm{L}$ to $\mathrm{mg} / \mathrm{dL}$, $\times 4.0$; phosphate in $\mathrm{mmol} / \mathrm{L}$ to $\mathrm{mg} / \mathrm{dL}, \times 3.1 ; i P T H$ in $\mathrm{pg} / \mathrm{ml}$ to $\mathrm{pmol} / \mathrm{L}, \times 0.11$. No conversion is necessary for ALP, PAB, hs-CRP and NT-proBNP.

Table 2. Predictive value of parameters of calcium, phosphate and iPTH for cardiovascular mortality by univariable Cox regression model 


\begin{tabular}{|c|c|c|c|}
\hline \multirow[t]{2}{*}{ Parameters } & \multicolumn{3}{|c|}{ CVD mortality } \\
\hline & $\mathrm{HR}$ & $\mathrm{P}$ & $95 \% \mathrm{Cl}$ \\
\hline Baseline serum calcium & 0.408 & 0.224 & $0.096-1.729$ \\
\hline Baseline serum phosphate & 1.820 & 0.129 & $0.840-3.945$ \\
\hline Baseline serum iPTH & 1.003 & 0.525 & $0.992-1.011$ \\
\hline One-year mean serum calcium & 0.910 & 0.892 & $0.236-3.512$ \\
\hline One-year mean serum phosphate & 1.015 & 0.965 & $0.507-2.032$ \\
\hline One-year mean serum iPTH & 1.001 & 0.158 & $0.998-1.002$ \\
\hline One-year serum calcium variability & 0.834 & 0.459 & $0.522-1.264$ \\
\hline One-year serum phosphate variability & 0.201 & 0.477 & $0.002-16.754$ \\
\hline One-year serum iPTH variability & 1.002 & 0.978 & $0.991-1.009$ \\
\hline One-year achievement rate of serum calcium & - & - & - \\
\hline Proportion $=0 \%$ & 1.042 & 0.947 & $0.305-3.557$ \\
\hline Proportion $=25 \%$ & 1.961 & 0.116 & $0.846-4.545$ \\
\hline Proportion $=50 \%$ & 1.157 & 0.734 & $0.499-2.680$ \\
\hline Proportion=75\% & 1.115 & 0.799 & $0.481-2.586$ \\
\hline Proportion $=100 \%$ & Ref & - & - \\
\hline One-year achievement rate of serum iPTH & - & - & - \\
\hline Proportion $=0 \%$ & 1.554 & 0.394 & $0.563-4.288$ \\
\hline Proportion=25\% & 1.39 & 0.538 & $0.487-3.966$ \\
\hline Proportion $=50 \%$ & 1.507 & 0.362 & $0.624-3.638$ \\
\hline Proportion=75\% & 0.688 & 0.523 & $0.218-2.168$ \\
\hline Proportion $=100 \%$ & Ref & - & - \\
\hline One-year achievement rate of serum phosphate & - & - & - \\
\hline Proportion $=0 \%$ & 4.381 & 0.018 & $1.779-17.283$ \\
\hline Proportion=25\% & 3.244 & 0.025 & $1.156-9.105$ \\
\hline Proportion $=50 \%$ & 1.786 & 0.282 & $0.620-5.141$ \\
\hline Proportion $=75 \%$ & 1.494 & 0.493 & $0.474-4.708$ \\
\hline Proportion=100\% & Ref & - & - \\
\hline
\end{tabular}


Note: Abbreviations: iPTH, intact parathyroid hormone;

The calculation of one-year achievement rate of serum phosphate was the target-achieving times divided by the total four times in one year. The "Single" referred to the value of the baseline.

Table 3. Cox regression analysis for the associations of various parameters and CVD mortality

\begin{tabular}{|c|c|c|c|c|c|}
\hline \multirow[t]{2}{*}{ Characteristics } & \multicolumn{2}{|c|}{ Univariable } & \multicolumn{3}{|c|}{ Multivariable } \\
\hline & $\mathrm{HR}$ & $\mathrm{P}$ & $\mathrm{HR}$ & $\mathrm{P}$ & $95 \% \mathrm{Cl}$ \\
\hline Age & 1.076 & $<0.001$ & 1.049 & 0.005 & $1.015-1.084$ \\
\hline Male & 2.053 & 0.026 & & & \\
\hline Dialysis age (month) & 0.999 & 0.868 & & & \\
\hline Diabetes mellitus & 2.773 & 0.001 & 1.979 & 0.039 & $1.036-3.778$ \\
\hline Cardiovascular disease & 3.463 & $<0.001$ & 2.79 & 0.002 & $1.468-5.303$ \\
\hline History of malignant tumor & 1.711 & 0.193 & & & \\
\hline History of kidney transplantation & 0.258 & 0.045 & & & \\
\hline One-year achievement rate of serum phosphate & - & 0.027 & - & 0.041 & - \\
\hline Proportion=0\% & 4.381 & 0.012 & 4.117 & 0.016 & $1.305-12.986$ \\
\hline Proportion $=25 \%$ & 3.244 & 0.025 & 3.343 & 0.023 & $1.177-9.494$ \\
\hline Proportion $=50 \%$ & 1.786 & 0.282 & 2.129 & 0.162 & $0.738-6.144$ \\
\hline Proportion $=75 \%$ & 1.494 & 0.493 & 1.080 & 0.902 & $0.318-3.665$ \\
\hline Proportion $=100 \%$ & - & Ref & - & Ref & - \\
\hline One-year mean of $\mathrm{Hb}(\mathrm{g} / \mathrm{L})$ & 0.988 & 0.366 & & & \\
\hline One-year mean of $\mathrm{Alb}(\mathrm{g} / \mathrm{L})$ & 0.823 & $<0.001$ & 0.848 & 0.002 & $0.762-0.943$ \\
\hline One-year mean of PAB(mg/L) & 0.990 & $<0.001$ & & & \\
\hline One-year mean of hs-CRP(mg/L) & 1.025 & 0.009 & & & \\
\hline One-year mean of NT-proBNP(pg/ml) & 1.001 & 0.001 & & & \\
\hline One-year mean of nPCR & 0.184 & 0.044 & & & \\
\hline One-year mean of spKt/V & 0.113 & 0.009 & & & \\
\hline One-year mean of URR & 0.001 & 0.003 & & & \\
\hline
\end{tabular}


Note: Abbreviations: iPTH, intact parathyroid hormone; ALP, alkaline phosphatase; Alb, albumin; $\mathrm{Hb}$, hemoglobin; PAB, prealbumin; hs-CRP, high-sensitive C-reactive protein; nPCR, normalized protein catabolic rate; URR, urea reduction ratio.

Parameters including one-year mean of ALP, Hb, Alb, PAB, hs-CRP, NT-proBNP, nPCR, spKt/V and URR were enrolled using the mean value of four examinations in a year. The calculation of one-year achievement rate of serum phosphate was the target-achieving times divided by the total four times in one year.

Table 4. Multivariate mixed-effects logistic regression analysis of related factors for one-year achievement rate of serum phosphate.

\begin{tabular}{|llllll|}
\hline Characteristics & \multicolumn{4}{l}{ Univariable } & \multicolumn{2}{l}{ Multivariable } \\
\cline { 2 - 6 } & OR & P & OR & P & $95 \% \mathrm{Cl}$ \\
\hline Age & 1.026 & 0.015 & 1.162 & 0.219 & $0.991-1.040$ \\
\hline Male sex & 1.766 & 0.027 & 1.447 & 0.237 & $0.784-2.671$ \\
\hline Dialysis age & 1.002 & 0.174 & & & \\
\hline Serum Ca & 2.054 & 0.088 & & & \\
\hline Serum iPTH & 0.998 & $<0.001$ & 0.922 & $<0.001$ & $0.903-0.950$ \\
\hline ALP & 0.968 & $<0.001$ & 0.975 & $<0.001$ & $0.967-0.983$ \\
\hline Alb & 0.974 & 0.403 & & & \\
\hline PAB & 0.996 & 0.069 & & & \\
\hline nPCR & 0.139 & 0.001 & 0.114 & $<0.001$ & $0.036-0.366$ \\
\hline spKt/V & 4.265 & 0.005 & & & \\
\hline URR & 5.202 & $<0.001$ & 2.598 & 0.007 & $2.393-3.924$ \\
\hline NT-proBNP & 1.001 & 0.138 & & & \\
\hline Total Phosphate-binding capacity & 0.997 & 0.002 & 0.997 & 0.023 & $0.995-0.999$ \\
\hline Calcitriol & 0.955 & 0.017 & 1.001 & 0.972 & $0.959-1.045$ \\
\hline Cinacalcet & 1.459 & 0.252 & & & \\
\hline
\end{tabular}

Note: Abbreviations: iPTH, intact parathyroid hormone; ALP, alkaline phosphatase; Alb, albumin; $\mathrm{Hb}$, hemoglobin; PAB, prealbumin; hs-CRP, high-sensitive C-reactive protein; nPCR, normalized protein catabolic rate; URR, urea reduction ratio. 
Parameters including ALP, Hb, Alb, PAB, hs-CRP, NT-proBNP, nPCR, spKt/V and URR are enrolled using the value of each visit during the first follow-up year. Dose of calcitriol and whether to use cinacalcet are recorded at each visit.

Parameters including age, dialysis age, serum calcium, iPTH, ALP, Alb, PAB, nPCR, spKt/V, URR, NTproBNP, total Pi-binding capacity, calcitriol are continuous variables while sex and cinacalcet are binary variables. The calculation of one-year achievement rate of serum phosphate was the target-achieving times divided by the total four times in one year.

\section{Figures}
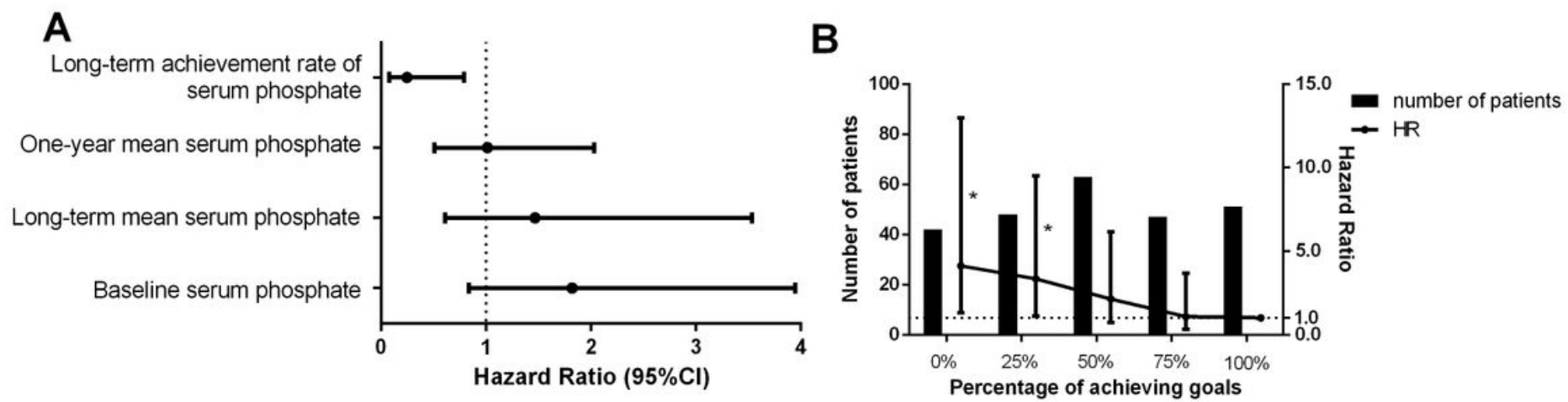

\section{Figure 1}

Association between serum phosphate indicators and CVD mortality in maintenance hemodialysis patients. Note: A. Association between baseline, long-term and one-year serum phosphate indicators and CVD mortality by univariate Cox regression analysis. B. Association between one-year achievement rate of serum phosphate and CVD mortality adjusted for age, diabetes mellitus, history of cardiovascular disease and one-year mean of serum albumin. HR, hazard ratio; $95 \% \mathrm{Cl}, 95 \%$ confidence interval. The calculation of one-year achievement rate of serum phosphate was the target-achieving times divided by the total four times in one year. ${ }^{*} \mathrm{P}<0.05$ compared to the group "One-year achievement rate of serum phosphate $=100 \% "$. 


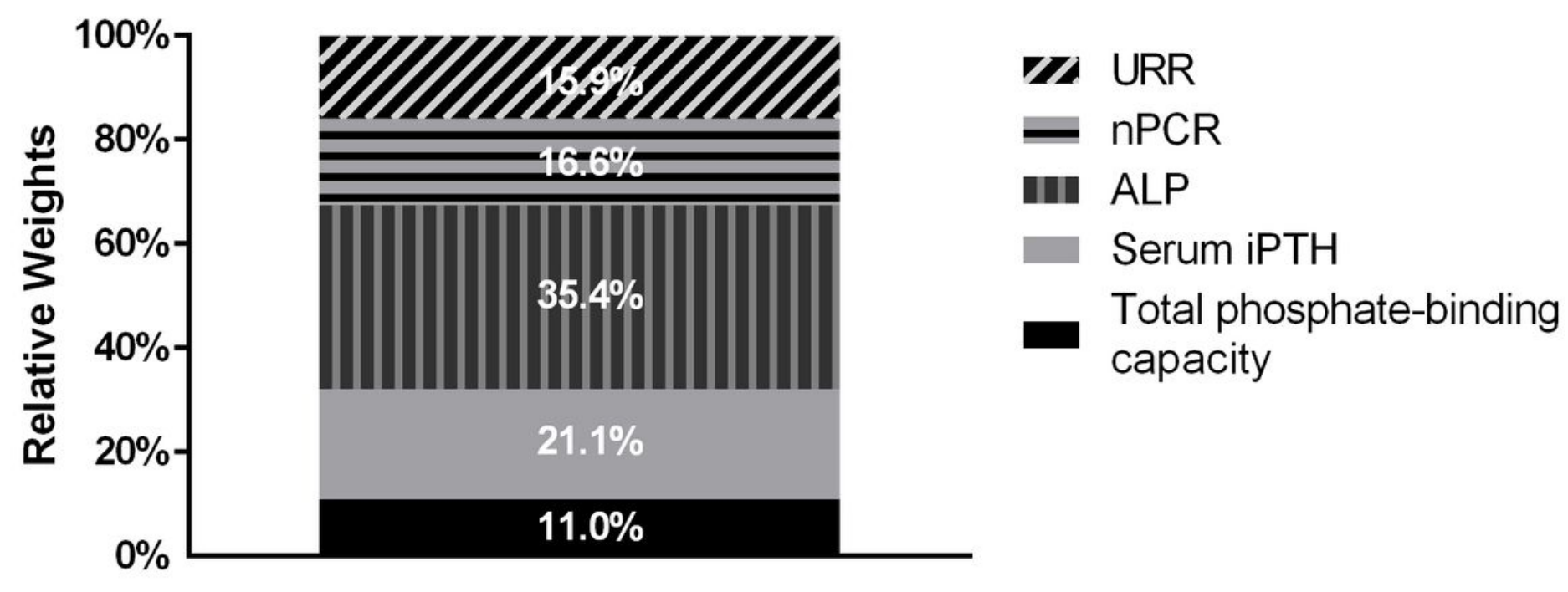

Figure 2

Relative weights of related factors for target achievement of serum phosphate in single time-point examination. Note: Abbreviations: iPTH, intact parathyroid hormone; ALP, alkaline phosphatase; nPCR, normalized protein catabolic rate; URR, urea reduction ratio.

\section{Supplementary Files}

This is a list of supplementary files associated with this preprint. Click to download.

- SupplementalMaterials.pdf 